\title{
Optimal Lot-Sizing Algorithms on Stochastic Demand at the Retailer
}

Edy Fradinata

Industrial Engineering Department, Syiah Kuala University, Banda Aceh, Indonesia

\author{
Zulnila Marli Kesuma
}

Statistics Department, Faculty of Mathematics and Natural Science, Syiah Kuala

University, Banda Aceh, Indonesia

Siti Rusdiana

Mathematics Department, Faculty of Mathematics and Natural Science, Syiah

Kuala University, Banda Aceh, Indonesia

\begin{abstract}
Purpose - The purpose of this study is to explore the concept of the economic lot sizing and the time cycle period of reordering. The stochastic demand is quite common in the real environment of a cement retailer. The study compares three methods to obtain the optimal solution of a lot-sizing ordering from the real case of the previous study where the dataset is collected from the area of some retailers at Banda Aceh Province of Indonesia.
\end{abstract}

Design/Methodology/Approach - The problem model appears when the retailer with shortage has to fulfill the lot size in the optimal condition to the stochastic demand while at the same time has the backlog condition. Moreover, when the backorder needs the time horizon for replenishment where this condition influences the holding cost at the store, many retailers try to solve this problem to minimize the holding cost, but on the other side, it should fulfill the customer demand. Three methods are explored to identify that condition: a Wagner-Whitin algorithm, the Silver-Meal heuristic, and the holding and ordering costs. The three methods are applied to the lot sizing when there is a backlog.

Findings - The results of this study show that the Wagner-Whitin algorithm outperforms the other two methods. It shows that the performance increases around $27 \%$ when compared to the two other methods in this study.

Research Limitations/Implications - All models are almost approximate and useful to determine the cycle period on stochastic demand.

Practical Implications - The calculation of the dataset with the three methods would give the simple example to the retailer when he faces the uncertainty demand models. The prediction of the calculation is done accurately than the constant calculation, which is more economic.

Social Implications - The calculation will contribute to much better predictions in many cases of uncertainty.

Originality/Value - This is a initial comparative model among other methods to achieve the optimal stock and order for a retailer

Keywords Wagner-Whitin algorithm, Silver-Meal heuristic, holding and ordering costs, optimal quantity

(C) Edy Fradinata, Zulnila Marli Kesuma, Siti Rusdiana. Published in the Emerald Reach Proceedings Series. Published by Emerald Publishing Limited. This article is published under the Creative Commons Attribution (CC BY 4.0) licence. Anyone may reproduce, distribute, translate and create derivative works of this article (for both commercial and non-commercial purposes), subject to full attribution to the original publication and authors. The full terms of this licence may be seen at http://creativecommons.org/licences/by/4.0/legalcode

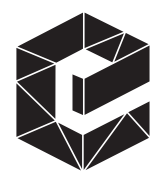


Proceedings of MICoMS 2017

All papers within this proceedings volume have been peer reviewed by the scientific committee of the Malikussaleh International Conference on Multidisciplinary Studies (MICoMS 2017).

\section{Introduction}

In the real environment, the probability of variance should influence the customer demand at the retailer level. The retailer's inventory is reviewed periodically in a certain interval of time where the goods would be ordered after review. The modified policy can be used where the interval is in the short condition. It is called the $(Q, R)$ policy. The $(Q, R)$ policy should be implemented when the inventory level drops to the reorder point when the warehouse places an order. This condition is solved with the inventory system that has the two-notation $s$ and $S$ policy while the stock goes over. It means the inventory drops under $s$ and it starts to increase to the $S$ level. This situation generally is called the modified $(Q, R)$ policy of an $(s, S)$. In this situation, it is hard to define the optimal condition of $s$ and $S$ for the stochastic model. The simple way is to find the values, and it usually uses the calculation of $Q$ and $R$ values where this strategy continues to review the model; in this case the $s$ is settled to $R$ and $S$ equals $R+Q$.

This environment, the warehouse, keeps the base stock level parameter to keep the stock safely. Furthermore, the warehouse must calculate to fulfill the stock level at the point of based stock level and the suitable order for each period. It should be done after the stock is reviewed in the warehouse and then it is increased to the base stock level after the order. This condition protects the warehouse from the shortage while waiting for the replacement process of goods. It means that the order arrives after a period where the current order could fulfill the demand for the period (Simchi-Levi et al., 1999).

Reorder point for continuous review policy $(R, Q)$ is under simple assumptions with reorder point $(R)$, is zero since the lead-time $(L)$ is zero. It means that the order starts when the stock in the warehouse is zero and the delivery should be sent immediately. The problem then appears when managing the warehouse with reordering to care for the shortage for anticipating the stochastic demand, based on the forecast time horizon demand (Fradinata et al., 2014). In this situation, the Wagner-Whitin algorithm, Silver Meal heuristic, and holding and ordering costs try to solve the dynamic order of lot-sizing problem situation.

The contribution of this paper is to compare the three methods and to choose the optimal condition based on the algorithm in managing the warehouse for reorder at the retailer level.

\section{The methods}

\subsection{Data collection}

Some cement retailers in the Banda Aceh district were used for data collection. The data have the characteristic of stochastic demand from a customer in one year with per month basis. The signal demand is shown in Figure 1.

\subsection{Reorder point}

Reorder point is the order of goods to the factory when replenishing the particular inventory stock plus the safety stock at a certain period. The level equalization of the inventory position with the stock level is when the lead time $L>0$, which means that the batch unit at $L$ time has ordered earlier, reorder point is changed to $R=L d$. 


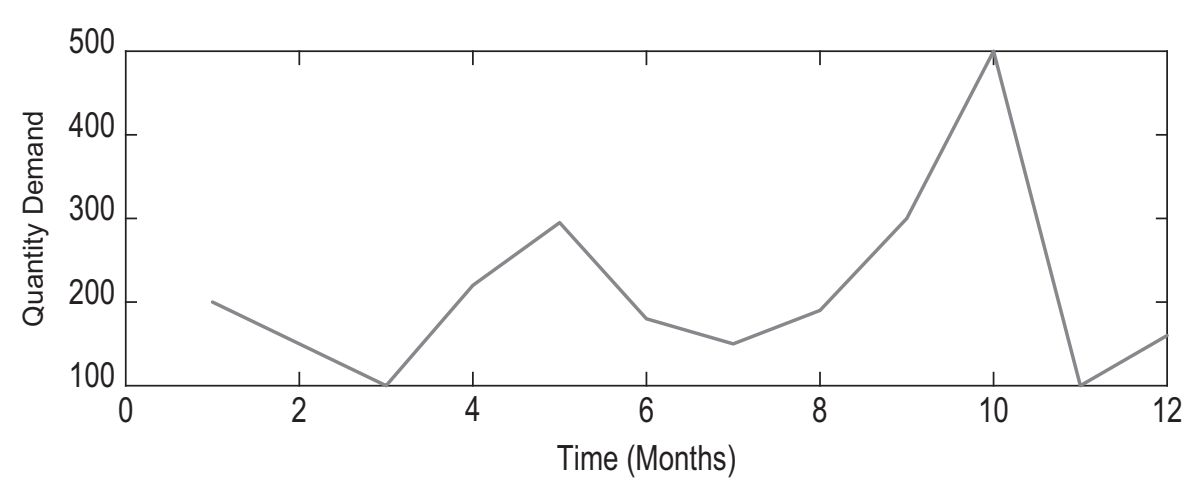

Optimal Lot-Sizing Algorithms the Retailer Level

\subsection{Time-varying demand}

Demand variation is mostly used in the real world due to the variations caused by the customer need or by other reasons. The products can be produced based on a certain customer need by the factory. The factory should be on a contract with the retailer where it must send a certain quantity on a specific date based on the agreement (Fradinata et al, 2015).

When the factory agrees to produce a lot sizing on the stochastic demand, it is mostly expected that the production is a determinate amount of separate time between periods (Axsäter, 1996). The period can be defined in a cycle of time in the day, week, and month. It is considered that the demand period can be the starting point of the first period since there is no stock at the first time when conveying a lot size; the lot size or batch is at a certain time of the period (Fradinata et al., 2017). The holding and ordering costs are assumed constant over time where no backorder is allowed. It can be described in the following notation. The notation $T$ is the number of periods, $d_{i}$ is the demand for the period of $i, i=1,2, \ldots ., T$, (with $d_{i}>0$ ). $A$ is the ordering cost. $h$ is the holding cost per unit.

The methods of ordering and holding costs have the purpose of minimizing batch quantities. The stochastic demand has a different quantity at a different time with optimal lot sizes (Axsäter, 1982).

\subsection{The Wagner-Whitin algorithm}

Dynamic programming is the most common approach where it was suggested by the Wagner and Within (1958) algorithm, described in the notation, that $f_{k}$ is the minimum cost of $k+1, k+2, T$ and $f_{k, i}$ is the minimum cost of $1,2, \ldots, k$, when the last delivery period is $t$ $(1 \leq t \leq k)$. The form formula is

$$
f_{k}=\min _{1 \leq i \leq k} f_{k, i},
$$

The optimal solution is sent by the last delivery. It is clear that $f_{o}=0$ and that $f_{1}=f_{1,1}=\mathrm{A}$. This is because in one period we get the setup cost and no holding costs. This is assumed that the beginning period appears to be the demand period. We assume that if $f_{t-1}$ at the value of $t>0$, it is then easy to obtain $f_{k, t}$ for $k \geq t$ as

$$
f_{k, i}=f_{t-1}+A+h\left(d_{i+1}+2 d_{t+2}+\cdots+(k-t) d_{t+2}+\cdots \ldots+(k-t) d_{k}\right)
$$

Since the delivery period has the value of $t$, then $f_{t-1}$ is the minimum cost. The setup cost is $A$ in each period. It is assumed that the initial period has the demand in the first 
Proceedings of MICoMS 2017 time. It means that $d_{t}$ is not a holding cost. This combination is $h d_{t+1}$. The period demand $t+2$ is kept in stock during two periods, $t$ and $t+1$, and the holding cost could be $2 h d_{t+1}$, etc.

The value of $f_{1}, f_{2}, \ldots, f_{k-1}$ can solve the problem for the periods. Then, we can determine $f_{k}$, for $1 \leq t \leq k$ from formula (2) and also solve for $k$ periods (1), after which we can use the procedure for $k+1$ periods, etc. Furthermore, when applying (2) it is obvious that we just need to consider $k \leq T$. After all $T$ periods are obtained, it follows the steps: first, use (1) for $k=\mathrm{T}$, and the minimum of $t$ by $t^{\prime}$. After that, recalculate again (1) for $k=t^{\prime}(1$ for the last supply $t$ ". Next, it considers (1) for $k=t$ ' $(1$, and it continues until obtaining the minimizing $t$ which equals with the deliveries (Axsäter, 1980).

The variables are the demand $(T)$ with 12 periods. $A$ notation is the ordering cost for $\$ 350$, and $h$ is the holding cost for $\$ 1 /$ unit of the period. Then set $f_{1,1}=350$, and then use Eq. (2) to determine $f_{2,1}=f_{1,1}+1 * 150=500, f_{3,1}=f_{2,1}+2 * 100=700$, etc., on the $f_{6,1}$ it is noted that the holding cost connected to the demand in period 6 is $450>A=350$. Let the value of $f$ be $f_{1}=f_{1,1}=350$. Applying (2) from here, $f_{2,1}, f_{2,2}$, etc are obtained. After completing, use Eq. (1) to get $f_{2}=\min \left\{f_{2,1}, f_{2,2}\right\}=\min \{1,360,1,050,1,050,1,050\}=1,050$. These are from the diagonal in Table 1 , where it is optimized to the right to obtain $f_{3}=\min \{1,360,1,050$, $1,000,1,050\}=1,000$ and this is continued until the table completes. Finally, the minimum $\operatorname{cost} f_{12}=\min \{11,080,100,10,11,510,15,110,17,930\}=10,010$ is obtained by applying (1).

The minimum cost is obtained for both $t^{\prime}=10$ and $i^{\prime}=8$. Reflect that $t^{\prime}$ is 10 . Then we get 8 , where the optimality must be reached over eight periods. By looking at the equivalent diagonal, $t$ " is 4 and $t$ " is 4 . Finally, $t$ "' is 1 and the solution is complete. Table 2 shows optimal solutions to brief the condition of the dataset.

\subsection{The Silver-Meal heuristic}

The concept of Silver-Meal heuristic is to select the new amount of delivery when there is an increase in the value at the beginning of the average per period costs. It means that the initial delivery should be calculated over $n$ periods and the next period in $n+1$ :

$$
\frac{A+h \sum_{j=2}^{k}(j-1) d_{j}}{k} \leq \frac{A+h \sum_{j=2}^{k}(j-1) d_{j}}{k-1}, 2 \leq k \leq n,
$$

and

$$
\frac{A+h \sum_{j=2}^{n+1}(j-1) d_{j}}{n+1}>\frac{A+h \sum_{j=2}^{n+1}(j-1) d_{j}}{n}
$$

Table 1.

Solution of $f_{k, t}$ From the Variation

Demand

\begin{tabular}{lcrrrrrrrrrrr}
\hline Period $t$ & 1 & 2 & \multicolumn{1}{c}{3} & \multicolumn{1}{c}{4} & \multicolumn{1}{c}{5} & \multicolumn{1}{c}{6} & 7 & 8 & 9 & 10 & 11 & 12 \\
\hline$d_{t}$ & 200 & 150 & 100 & 220 & 295 & 180 & 150 & 190 & 300 & 500 & 400 & 160 \\
$k=t$ & 350 & 700 & 850 & 1,050 & 1,710 & 2,890 & 3,790 & 4,690 & 6,020 & 8,420 & 12,920 & 16,920 \\
$k=t+1$ & 500 & 850 & 1,050 & 1,200 & 1,860 & 3,040 & 3,940 & 4,840 & 6,170 & 8,570 & 13,070 & 17,070 \\
$k=t+2$ & 700 & 1,050 & 1,150 & 1,400 & 2,060 & 3,240 & 4,140 & 5,040 & 6,370 & 8,770 & 13,270 & 17,270 \\
$k=t+3$ & 1,360 & 1,710 & 1,350 & 2,060 & 2,720 & 3,900 & 4,800 & 5,700 & 7,030 & 9,430 & 13,930 & 17,930 \\
$k=t+4$ & 2,540 & & 1,550 & 3,240 & 3,900 & 5,080 & 5,980 & 6,880 & 8,210 & 10,610 & 15,110 & \\
$k=t+5$ & 3,440 & & 1,750 & 4,140 & & 5,980 & 6,880 & 7,780 & 9,110 & 11,510 & 16,010 & \\
$k=t+6$ & 4,770 & & 2,410 & & & 6,880 & & 8,680 & 10,010 & & & \\
\hline
\end{tabular}


The calculation of this study presented in Table 3 shows that Period 1 covers the demand in the period 1 with the ordering cost of $\$ 350$.

\subsection{Balanced holding and ordering costs heuristic}

Holding and ordering costs heuristic can be used to identify the optimal solution for the stochastic lot size problem. In this matter, holding and ordering costs are the same size as the following algorithm, $n$ periods cover the first delivery quantity and $n$ is given by the following formula:

$$
h \sum_{j=2}^{n}(j-1) d_{j} \leq A \leq h \sum_{j=2}^{n+1}(j-1) d_{j}
$$

When the ordering cost exceeds the holding cost, it is chosen as a new delivery where the next lot size is calculated in a similar way in the period $n+1$.

\section{Result and discussion}

\subsection{Wagner-Whitin algorithm}

Table 1 shows the demand in 12 horizontal timelines with the variation stochastic demand $\left(d_{t}\right)$. The Wagner-Within algorithm was general with the backlog problem. The view of the optimal solution in Table 1 indicates the computational complexity. This method has the ability to solve the dynamic lot size problem with the cycle horizon. It determines the lot sizes in each first cycle of the period. The time horizon is

\begin{tabular}{lcccccccccccc}
\hline Period $t$ & 1 & 2 & 3 & 4 & 5 & 6 & 7 & 8 & 9 & 10 & 11 & 12 \\
\hline Optimal 1 & 250 & & 625 & 1,360 & &
\end{tabular}

Table 2. Optimal Solution Batch Size

\begin{tabular}{lcccccccccccr}
\hline Period $t$ & 1 & 2 & 3 & 4 & 5 & 6 & 7 & 8 & 9 & 10 & 11 & 12 \\
\hline$d_{t}$ & 450 & & & 475 & & 340 & & 1,060 & & & & $\begin{array}{r}\text { Silver-Meal solution } \\
\text { in Periods }\end{array}$ \\
\hline
\end{tabular}

\begin{tabular}{lcccccccccccr}
\hline Period $t$ & 1 & 2 & 3 & 4 & 5 & 6 & 7 & 8 & 9 & 10 & 11 & 12 \\
\hline$d_{t}$ & 450 & & 625 & & & 190 & & 1,060 & & & $\begin{array}{r}\text { Table 4. } \\
\text { Solution Holding and } \\
\text { Ordering Costs } \\
\text { Heuristic }\end{array}$ \\
\hline
\end{tabular}

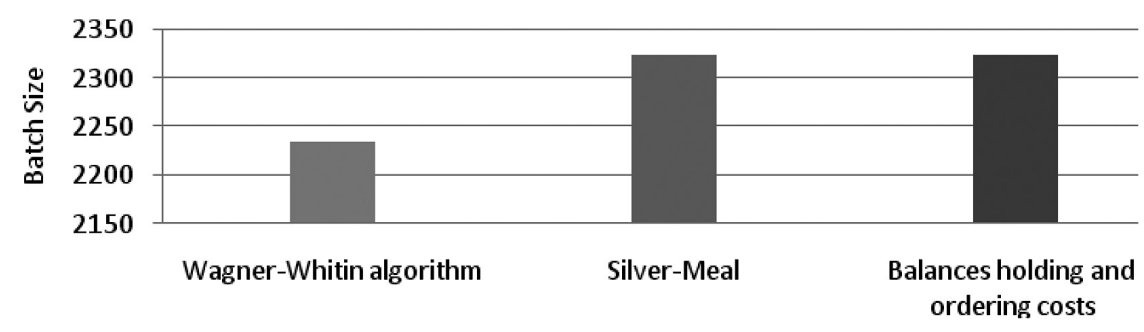

Figure 2. A Comparison of the Methods to the Total Batch Size Per Year 
Proceedings of infinite but in this case uses the approximation of the finite horizon. Optimal solutions MICoMS 2017 are at $t=1,4$, and 8, and then the total batch size is 2,235 .

\subsection{Silver-Meal heuristic}

This method is simple and the most commonly used in the real situation of the single retailer to plan the order of the backlog condition. The optimal condition is shown in Table 3.

Table 3 shows that the batch size for the order in periods $t=1,4,6$, and 9 . The result is $450,475,340$, and 1,060 respectively. It means that the order in a year should be 2,325 . Then it continues to the third step, etc.

\subsection{Balanced holding and ordering costs heuristic}

The condition of the dataset is used to determine the optimal solution of gathering from holding costs to ordering cost. The result is described in Table 4. It is simple to verify that it obtains the same as the Silver-Meal heuristic.

Table 4 shows that the result of the batch size in periods are $t=1,4,7$, and 9 with the amount of 450,625, 190, and 1,060 respectively. The total batch size order for a year is 2,325. It has the lead time which varies for difference backorder. In the real situation may be there are a very few backlog conditions while waiting for the replenishment time. Allowing the backorders means that a number of goods could be supplied after it has been requested by the retailer. Furthermore, the quantity of batch $Q$ is delivered for $x$-factors.

Figure 2 illustrates that the total efficiency cost using the Wagner-Whitin algorithm is the most economic with $2235(\$ 1)=\$ .2235$, then followed by the Silver-Meal with $\$ .2325$ and the holding and ordering cost methods with $\$ .2325$. The two other methods are approximate.

\section{Conclusion}

The study is to identify the inventory control at the warehouse with three methods: Wagner-Whitin algorithm, Silver-Meal, and holding and ordering costs in stochastic demand at the retailer level in Banda Aceh. One of the problems in the warehouse is when managing the order to take care of the shortage of stochastic demand. The result is that the Wagner-Whitin algorithm outperformed the other methods, Silver-Meal and holding and ordering costs, in this study. The Silver-Meal and the holding and ordering costs showed the approximate results. The efficiency of the Wagner-Whitin algorithm is $27 \%$ higher compared to the two other methods. It means that the Wagner-Within algorithm is more economic than other methods. The horizontal periods have a different cycle for each method due to the characteristic of the stochastic demand.

\section{References}

Axsäter, S. (1980). "Economic Lot Sizes and Vehicle Scheduling”. European Journal of Operational Research, Vol. 4, No. 6, pp. 395-398.

Axsäter, S. (1982). "Worst Case Performance for Lot Sizing Heuristics". European Journal of Operational Research, Vol. 9, No. 4, pp. 339-343.

Axsäter, S. (1996). "Using the Deterministic EOQ Formula in Stochastic Inventory Control" Management Science, Vol. 42, No. 6, pp. 830-834.

Fradinata, E., Sirivongpaisal, N., Suthummanon, S. and Suntiamorntuth, W. (2014). "ANN, ARIMA and MA Time Series Model for Forecasting in Cement Manufacturing Industry: Case Study at Lafarge Cement Indonesia-Aceh". In 2014 IEEE International Conference of Advanced Informatics: Concept, Theory and Application (ICAICTA). 
Fradinata, E., Suthummanon, S. and Suntiamorntuth, W. (2015). "Forecasting Determinant of Cement Demand in Indonesia with Artificial Neural Network". Journal of Asian Scientific Research, Vol. 5, No. 7, 373-384.

Fradinata, E., Suthummanon, S. and Suntiamorntuth, W. (2017). "Comparison of Hybrid ANN Models: A Case Study of Instant Noodle Industry in Indonesia”. International Journal of Advanced and Applied Sciences, Vol. 4, No. 8, pp. 19-28.

Simchi-Levi, D., Simchi-Levi, E. and Kaminsky, P. (1999). Designing and Managing the Supply Chain: Concepts, Strategies, and Cases, McGraw-Hill, New York.

Wagner, H. M. and Whitin, T. M. (1958). "Dynamic version of the economic lot size model", Management science, Vol. 5, pp. 89-96.

\section{Corresponding author}

Edy Fradinata can be contacted at edinata69@gmail.com 